\title{
Mortality salience and the Trolley Problem in Medical Students
}

\author{
Gabriel Andrade ${ }^{1 *}$, Maria Campo Redondo ${ }^{2} \&$ Deepali Razdan ${ }^{3}$ \\ ${ }^{1}$ School of Medicine, St. Matthew's University, Grand Cayman, Cayman Islands. \\ ${ }^{2}$ United Arab Emirates University, Abu Dhabi, United Arab Emirates. \\ ${ }^{3}$ School of Medicine, Xavier University, Oranjestad, Auba.
}

Received 25.09.2018; Received revised 3.12.2018; Accepted 10.12.2018

Available online 31.12.2018

\begin{abstract}
Terror Management Theory predicts that when subjects are exposed to mortality salience (i.e. they are reminded of their death), they develop higher levels of anxiety and have stronger holdings for their cultural worldviews. Mortality salience also makes subjects more cautious in many daily activities. These premises lead to the hypothesis that, under mortality salience, subjects are more deontological in their moral judgments. To test this hypothesis, medical students from a Caribbean school were presented with two classical versions of the Trolley Problem. Subjects were placed in two groups, on the basis of a computer random generator. One group was not exposed to mortality salience, the other group was. Results came out showing that being under mortality salience does not significantly increase the probability that subjects have a deontological approach to ethics.
\end{abstract}

Keywords: mortality salience, trolley problem, medical students, ethics, terror management theory.

Address of correspondence: Gabriel Andrade, School of Medicine, St. Matthew's University, Lime Tree Bay Ave, West Bay, Grand Cayman, Cayman Islands.

E-mail: Gabrielernesto2000@gmail.com

\section{Introduction}

Humans are notoriously the only species that are fully conscious of death. As Kropf (2004, p.103) remarks, "...animals can indeed fear or shun death, but only humans can know death in anticipatory awareness, not only knowing death as a phenomenon around us, but 'knowing that we know' and dreading the revelation of that which we cannot escape".

Alas, the knowledge of our own mortality causes terror in most people, and this has important psychological implications. These implications have been thoroughly studied by proponents of Terror Management Theory. This theory was originally formulated as an expansion of Ernest Becker's philosophical views. In The Denial of Death, Becker (2007) explored how the fear of death causes great anxiety, and this anxiety further drives humans to attempt to leave some kind of legacy via both constructive and destructive means. Becker interpreted great works of art as artists' attempts to achieve some kind of immortality; but he also warned that the fear of death has the potential to lead to authoritarian views that ultimately pave the way for totalitarian systems.

Proponents of Terror Management Theory sought to empirically test some of Becker's assertions (Harvell and
Nisbett, 2016). In a landmark study, Rosenblatt et al. (1989) studied two groups of judges. One group was reminded of death via questions relating to their own mortality. The other group was asked neutral questions that were not related to death. Then, both groups were presented with the hypothetical case of a prostitute, and were asked to dictate a punishment for her.

As it turned out, the group that had been exposed to reminders of death (i.e. the group with mortality salience) imposed significantly harsher punishments on the hypothetical prostitute. Rosenblatt et al. (1989) concluded that mortality salience tends to intensify subjects' adherence to their own cultural worldviews and values. Over 200 studies like this have been replicated with similar results (Greenberg, 2007, p. 593). Ways of making subjects salient to mortality could be by explicitly asking them about their own deaths, exposing them to death-related images, or even being close to funeral homes.

Despite the many variations on mortality salience experiments (Maxfield et al., 2010; Finch et al., 2016; Ben Ari et al., 1999), very few have actually studied the effects of exposure to death with making difficult moral decisions. Given the anxiety produced by being reminded of mortality, it can be predicted that subjects under mortality salience are more prone to making more conservative 
moral choices in critical situations. In fact, this has been confirmed by at least one study (Tremoliere et al., 2012).

The use of the so-called "Trolley Problem" is relevant in this regard (Edmonds, 2014). Originally formulated by philosopher Philippa Foot (1967), this problem poses an imaginary scenario: suppose a trolley is going down the tracks, and it is set on course to run down five people who are tied to the tracks. The driver of the trolley has the option to divert the trolley onto another track, in which only one person is tied. Foot wondered whether or not the driver should divert the trolley.

This dilemma comes down to two basic understandings of ethics: deontological vs. consequentialist (Tannsjo, 2008). In deontological ethics, there are intrinsic duties, and they must be carried out regardless of the consequences. In utilitarian ethics, consequences are important, and if an action brings about a greater amount of good, then it is considered moral. In this trolley scenario, refusing to divert the trolley would be the deontological option, inasmuch as there is the intrinsic duty not to participate in anyone's killing, even if that means not saving more people. By contrast, diverting the trolley would be approved by consequentialist ethics, because even if the action involved killing one person, it would save the five.

The Trolley Problem has some variations. In all variations, the prediction can be made that subjects under mortality salience will lean more towards the deontological option. The theoretical explanation for this is that, by being reminded of their own mortality, anxiety leads subjects to be more cautious in making decisions that may directly result in someone else's death. As documented by Vail and Juhl (2015), reminders of death have the potential of making people more cautious, in behaviors such as wearing seat belts, using sunscreen and doing exercise. Likewise, this caution may extend to moral judgments.

Medical students continuously encounter situations that remind them of death (Reynolds, 2006). And in their academic formation, they may occasionally encounter situations that structurally resemble the Trolley Problem. The question thus comes up: does being reminded of death make medical students more deontological in their decision making?

This is a relevant issue, as medical practitioners frequently encounter situations that require complex moral thinking. When it comes to issues such as euthanasia and abortion, many philosophers and medical ethicists complain that people's moral judgments on these issues tend to rely more on intuitions, and not on reasoned arguments, and therefore, are overly cautious (Singer, 1996). Inasmuch as health care professionals are an important group to consult when legislating things such as abortion and euthanasia, their moral leanings may ultimately be more reflected in policy and legislation, yet these deontological leanings may not come necessarily from adequate moral reasoning, but rather, from intuitive reactions as a result of their constant exposure to mortality salience.

\section{Method}

\section{Participants}

Xavier University School of Medicine, Aruba, has a population of 186 students, mostly of Canadian and American nationality, with very diverse ethnic origins. 56 students were approached to answer questions from a survey voluntarily, after signing Informed Consent forms. Subjects are evenly split on the basis of gender, their age span is between 19 and 38 years old, with a mean age of 23,7 .

\section{Measures and Procedure}

Two surveys were designed. The first survey asked introductory neutral questions, such as "What is your favorite TV show?", "What is your favorite movie?", "What is your favorite food?". The second survey had the purpose of placing subjects under mortality salience, by asking them questions that reminded them of their mortality. Some of these questions were "How do you think your relatives will dispose of your body when you die?", "How do you think you will be remembered by friends after you die?", "What do you think will be the most likely cause of your death?". These questions meant to make subjects think about their own death were based on (although not identical to) similar questionnaires used in other mortality salience studies (Miller and Mulligan, 2002; Pyszczynski et al, 1997).

On the basis of a computer random generator, 29 subjects were assigned to the first survey, and 27 subjects were assigned to the second survey. After being asked these introductory questions, both groups were then asked in their respective surveys what they would do in two variations of the Trolley Problem.

In the first variation, a trolley is going down its path, and it will run over five people. There is the option that a bystander pulls a lever and diverts the trolley onto another track, in which one person is tied. Subjects were asked whether they would pull the lever.

When the Trolley Problem began to be discussed seriously amongst philosophers after Foot's seminal article, most authors agreed that the ethical thing to do was to indeed, pull the lever, i.e., a consequentialist approach. But then, philosopher Judith Jarvis Thomson (1986, p. 109) formulated a second variation of the Trolley Problem, to test whether or not utilitarian solutions are easy to come by when facing the decision of saving one vs. saving five.

In this second variation, which was also included in the survey, a trolley is going on its path, and it is about to run over five people tied to the track. The trolley is about to go underneath a bridge; on that bridge, there is a fat man. If that fat man is pushed over the bridge, his weight will stop the oncoming trolley, he will die, but the five tied to the track will be saved. Subjects were asked if they would push the fat man.

Subjects were questioned personally. Inasmuch as mortality salience requires some time for thoughts to be processed, there was no time limit on each questioning. On average, respondents from the first group took 8 minutes to answer the whole questionnaire, while respondents from the second group took 15 minutes. No reward was given to the subjects, as their participation was entirely voluntary.

\section{Results}

In the scenario of a trolley going down a track with five persons tied, and having the option of pulling a lever to divert it to a track with only one person tied, $82 \%$ of the group not exposed to mortality salience approved of pulling lever, whereas $18 \%$ disapproved. Of the group that was exposed to mortality salience, $75 \%$ approved pulling the lever, whereas $25 \%$ disapproved (results are presented in Table 1). Using a significance level of 0.05 , the value of 
Chi Square comes out as being 0.62, and the p- value 0.42 . This means that the differences are non-significant.

In the scenario of a trolley going down a path with five people tied, and having the option of pushing a fat man from a bridge to stop the trolley, $52 \%$ of the group not exposed to mortality salience approved of pushing the fat man, whereas $48 \%$ disapproved. Of the group that was exposed to mortality salience, $48 \%$ approved of pushing the fat man, whereas $52 \%$ disapproved (results are presented in Table 2). Using a significance level of 0.05 , the value of Chi Square comes out as being 0.0715, and the p- value 0.789 . This means that the differences are, once again, non-significant.

The differences between the results in the two groups, and for both questions, are small and not statistically significant. In order to reach this conclusion, a Chi Square of Independence analysis was performed for both questions, with a 0.05 significance level.

Table 1. Pulling the lever (or not) in order to divert the trolley

\begin{tabular}{rllll}
\hline \multicolumn{1}{l}{} & \multicolumn{1}{l}{ Pulling the lever } & Not pulling the lever & Total \\
\hline$\checkmark$ & $\begin{array}{l}\text { Not exposed to } \\
\text { Mortality Salience } \\
\checkmark\end{array}$ & 5 & 29 \\
$\begin{array}{l}\text { Exposed to } \\
\text { Mortality Salience }\end{array}$ & 20 & 7 & 27 \\
\hline Total & & 12 & 56 \\
\hline
\end{tabular}

Table 2. Pushing the fat man (or not)

\begin{tabular}{rllll}
\hline \multicolumn{2}{c}{} & \multicolumn{1}{l}{ Pushing the fat man } & Not pushing the fat man & Total \\
\hline$\checkmark$ & $\begin{array}{l}\text { Not exposed to } \\
\text { mortality salience }\end{array}$ & 15 & 14 & 29 \\
$\checkmark$ & $\begin{array}{l}\text { Exposed } \\
\text { mortality salience }\end{array}$ & 13 & 14 & 27 \\
\hline Total & & 28 & 28 & 56 \\
\hline
\end{tabular}

\section{Discussion}

The initial hypothesis, according to which subjects under mortality salience become more deontological in their moral judgments, is not confirmed. The potential explanation for this finding may be that medical students are already desensitized to reminders of death in their in their daily clinical interactions, and in that sense, being exposed to mortality salience in specific situations does not make a difference from those moments when they are not exposed to mortality salience.

However, this finding only fails to confirm the hypothesis that medical students under mortality salience become more deontological in their moral judgments. It may very well be that, in the general population, subjects exposed to mortality salience do indeed become more deontological in their moral judgments.

This further invites studies comparing the moral judgments of medical students, and the moral judgments of regular subjects. A working hypothesis would be that medical education desensitizes students when it comes to mortality salience effects as applied to moral decisions, whereas mortality salience effects as applied to moral decisions do remain in the general population.

Indeed, relevant studies do seem to suggest that, as students go through training and finally go into the medical profession, their moral reasoning goes through some significant transformation, not necessarily towards a more mature understanding of morality or a higher level in Kohlberg's stages of moral reasoning, but rather, "a significant decrease in weighted average [moral] scores" (Patenaude, Niyonsenga, and Fafard, 2003). Likewise, Lind (2000) has documented that amongst medical students there are trends of moral regression during their medical education.

Nevertheless, although the initial hypothesis was not confirmed, it is still relevant that, in both groups, support for pulling the lever in the first case was much higher than support for pushing the fat man in the second case. $79 \%$ of subjects are willing to pull the lever, whereas only $50 \%$ of subjects are willing to push the fat man.

Other studies have consistently shown that, when it comes to pushing the fat man, subjects tend to be far less utilitarian (Tannsjo, 2015, p. 63). There seem to be two important moral reasons for this. First, there seems to be an important moral difference between actively participating in someone's death, and doing some action that only indirectly leads to someone's death (Kamn, 2001). Psychologically, pulling a lever to divert a trolley and letting one person die, is different than actually pushing someone from a bridge in order to kill him.

The second reason, related to the first, has to do with the relationship between means and ends (Di Nucci, 2014). In the case of the trolley diverted to another track, killing one person is only a side effect of saving the five, but never the means; if somehow the person tied to the tracks could escape, the goal would still be achieved. By contrast, in the case of the fat man being pushed from the bridge, the fat man's death would not just be a side effect, but rather, the means to save the five; if somehow the fat man bounced off and he survived, the goal would not be achieved, as the five would still die.

Subjects are not likely to have a formal understanding of these moral differences, but intuitively they understand that pulling the lever in the first case is of a different moral caliber than pushing the fat man in the second case. That 
seems to explain why pulling the lever gets consistently significant higher approval than pushing the fat man.

\section{Limits and future directions}

The obvious limitation of this study is sample size. Xavier University School of Medicine, Aruba, is a small off-shore Caribbean medical school. Inasmuch as medical students are under severe pressure for exams and study time, they are not completely available as subjects to answer a survey that in some cases can take 20 minutes. With a larger sample, perhaps the significant statistical effect posited in the original hypothesis could be confirmed.

Some additional questions could be asked in future surveys. If subjects are again medical students, they could be presented with more realistic hypothetical scenarios that have more resemblance to medical situations. Trolley Problem cases have been criticized because of their unrealistic nature (Gold, Pulfierd, Coleman, 2004). We chose to present the original Trolley Problem cases, given that there have not been prior studies discussing trolley cases under mortality salience. These more realistic scenarios could present subjects with cases of doctors having to decide to divert resources away from one patient in order to save five (thus substituting the Trolley scenario of pulling the lever); and cases in which the doctors have the option of deliberately harming one patient to save the five (thus substituting the Trolley scenario of pushing the fat man from the bridge). These experiments could also be carried out with general populations, and thus compare responses with respondents belonging to populations of medical students.

\section{Conclusion}

It appears that, as opposed to the common expectation, for medical students, being exposed to explicit reminders of death does not alter their moral judgments in difficult situations. The result may not be that surprising, if it is taken into account that, from the onset of their academic vocation, they constantly encounter both real and hypothetical scenarios that involve death, and may already be more desensitized than persons not working in the healthcare professions. The fact that they have been exposed to death for longer periods of time makes medical students less influenced by the effects of mortality salience. In that regard, medical students seem to differ from the rest of the population, who, under mortality salience, do become more deontological.

However, even if mortality salience does not alter medical students' moral judgments, they do still follow the trend of the general population when it comes to making a moral difference between killing one person and saving five, and killing one person as a means to save five.

\section{References}

Becker, E. (2007) The Denial of Death. New York: Simon and Schuster.

Ben-Ari, O. T., Florian, V., \& Mikulincer, M. (1999). The impact of mortality salience on reckless driving: A test of terror management mechanisms. Journal of Personality and Social Psychology, 76(1), 35-45.
Di Nucci, E. (2014). Ethics Without Intention. London: Bloomsbury.

Edmonds, D. (2014). Would You Kill the Fat Man?: The Trolley Problem and What Your Answer Tells Us about Right and Wrong. Princeton University Press.

Finch, E., Iverach, L., Menzies, R., \& Jones, M. (2016). "Terror mismanagement: evidence that mortality salience exacerbates attentional bias in social anxiety". Cognition and Emotion. 30(7): 1370-1379

Foot, P. (1967). The Problem of Abortion and the Doctrine of the Double Effect. Oxford Review, No. 5.

Gold, N., Pulford, B., \& Colman, A. (2014). The outlandish, the realistic, and the real: contextual manipulation and agent role effects in trolley problems. Frontiers in Psychology, 5, 35

Greenberg, J. (2007). Mortality Salience. Encyclopedia of Social Psychology. Baumeister, Roy and Vohs Kathleen (Eds.). London: Sage.

Harvell, L. \& Nisbett, G (Eds.) (2016). Denying Death: An Interdisciplinary Approach to Terror Management Theory. New York: Routledge.

Kamn, F (2001) Morality, Mortality: Volume II: Rights, Duties, and Status. Oxford University Press.

Kropf, R. (2004). Evil and Evolution: A Theodicy. Eugene: Wipf and Stock Publishers.

Lind, G. (2000). Moral regression in medical students and their learning environment. Revista Brasileira de Educacao Médica, 24(3), 24-33.

Maxfield, M., Solomon, S., Pyszczynski, T., \& Greenberg, J. (2010). "Mortality Salience Effects on the Life Expectancy Estimates of Older Adults as a Function of Neuroticism". Journal of Aging Research. 260123

Patenaude, J., Niyonsenga, T., \& Fafard, D. (2003). Changes in students' moral development during medical school: a cohort study. Canadian Medical Association Journal. 168(7), 840-844.

Pyszczynski, T., Greenberg, J., \& Solomon, S. (1997). "Why do we need what we need: a terror management perspective on the roots of human social motivation". Psychological Inquiry, 8, 1-20

Reynolds, F. (2006). How Doctors Cope with Death. Archives of Disease in Childhood. Sep. 91 (9).

Rosenblatt A., Greenberg J., Solomon S., Pyszczynski T., \& Lyon D. (1989) "Evidence for terror management theory: I. The effects of mortality salience on reactions to those who violate or uphold cultural values". Journal of Personality and Social Psychology. Oct; 57(4):681-90.

Singer, P. (1996). Rethinking Life and Death: The Collapse of Our Traditional Ethics. New York: Saint Martin's Griffin.

Tannsjo, T. (2008). Understanding Ethics. Edinburgh University Press.

Tannsjo, T. (2015). Taking life: Three Theories on the Ethics of Killing. Oxford University Press.

Thomson, J. (1986) Rights, Restitution, and Risk: Essays in Moral Theory. Harvard University Press.

Tremoliere, B., Neys, W.D., \& Bonnefon, J.F. (2012). Mortality salience and morality: thinking about death makes people less utilitarian. Cognition. 124 (3).

Vail, K. \& Juhl, J. (2015). An Appreciative View of the Brighter Side of Terror Management Processes. Social Sciences. 4, 1020-1045. 